\title{
Qualities of Coachers and Mentors - Defining Elements for Facilitating Performance
}

\author{
Micu Angela-Eliza \\ Ovidius University of Constanta, Romania \\ angelaelizamicu@,yahoo.com \\ Popa Daniel \\ Dunarea de Jos University of Galati, Romania \\ popadaniel.central@yahoo.com
}

\begin{abstract}
This paper was elaborated in order to synthesize the specialty literature on coaching and mentoring processes. The synthesis was made within papers originating in Western Europe and North America, spaces of tradition in the development of the approached topic. The idea of elaborating the paper started off the premise that coaching and mentoring processes are mostly influenced by the qualities of the coaches and mentors. Thus, the items ensuring the success in the field have been identified. The study is intended to represent the basis for future research, further to which are identified those qualities that are strictly required for the processes' success in Romania.
\end{abstract}

Key words: coaching, mentoring, strategies, qualities, performance, fsQCA, QCA

JEL Code: J21, J23, J24, M12, M53

\section{Introduction}

Along the professional activity, human resources go through various learning stages. In the first stage, they are subject to the learning process. Basic knowledge is thus accumulated, new opportunities are created and they develop on a personal level. According to Horne and Pine (1990) learning is a process activated by the person herself and takes place within. (Amin, 2005, p. 5). For performances' improvement further to the learning process, knowledge must be developed through training and coaching programmes.

The people having competences in various environments such as human resources, training, consultancy, management and education, possess relevant knowledge and skills that the coach can easily transfer. (Schein, 2009, p. 4-6)

\section{Theoretical background}

Coaching is a process characterized by:

- Most times, it is built based on a one-on-one relationship

- Most times it assumes the development of skills, aptitudes and/or performance improvement;

- It mandatorily involves a feedback process for the concerned person;

- It is built based on communication intended by the coacher to support not to impose. (Homan and Miller, 2008, pg. 7)

The coaching process offers benefits to all the parties involved. Although at first sight it seems to offer benefits only to the learner, the contrary is very often proven. Further to the coaching process, the coacher has benefits as well, consisting most of the times in the development of one's own skills and professional improvement. Therewith, the company that the person or the coacher works inbenefits from this coaching process by the change brought about within the inside environment. (Yeung, 2000, p.9)

The success of a coaching or mentoring process is largely connected to the coacher's capacities and skills. The programme beneficiary's features are also very important, without which the success is not ensured. Hereunder, we shall focus on the qualities coachers and mentors 
should have in order to ensure the success. Thus, we shall review the specialty literature on the approached topic.

A competent coacher, especially an executive coacher, is considered to have knowledge and competences in the following fields:

- psychology - understanding people's personality, motivation, learning and behavioural change, stress management, emotional intelligence, feedback, gender differences, social psychology;

- business - understanding basic notions about financial business and concepts, management principles and notions, strategic planning, information technology, global business dynamics, human resources management;

- organizational knowledge - understanding organizations' structures and functions, organizational design, organizational culture, team efficiency, leadership models, theory of systems, consultancy theories and practice, business ethnics, leadership development;

- coaching knowledge - understanding coaching theories and models, coaching competences, coaching-specific practices, coaching benefits, coaching research, coaching history. (HernezBroom and Boyce, 2011, p.92-93)

Rob Yeung considers that a coacher should have a strong desire to help other people, a proper attitude towards the process itself that is equivalent to professionalism, respect to the learner's choices, patience, developed sense of humour and the capacity to issue correct judgments. (Yeung, 2000, p.11-12)

Altruism mobilizes the coacher and its approach is oriented towards the beneficiary and, the most important thing, towards the latter's needs. Thus, we consider that the desire to help others is a key element defining a coacher's or mentor's quality and success.

The beneficiary's attitude towards the process is tightly connected to that of the coacher. Thus, the idea that the coacher is a guide is strengthened within the process. A good guide should prove respect, understand and accept the choices, opinions and nature of the other party.

Most of the times, both professionally and existentially, bottlenecks are easily eliminated by a positive attitude or a developed sense of humour. The need of this approach becomes imperative, especially within organizations where stress among employees is at high levels or the atmosphere is tense.

Douglas Reeves and Elle Allison emphasize other types of qualities. Thus, they remind in their paper that the important coachers' features are: listening capacity, capacity to ask mitigation questions, capacity to explain and describe theories, capacity to test theories, capacity to convey and receive feedback, brainstorming and customer mobilization capacity. (Reeves and Allison, 2010, p.104)

Another key feature of a coacher is the listening capacity. Theoretically, there are six types of listening: passive, false, competitive, selective, active and empathetic. The coacher must display an active listening.

It is paramount that the beneficiary sees that the issues he/she raises are of interest to the coacher and that they are taken into account. This aspect provides safety to the beneficiary who becomes more self-confident. Therewith, he also develops the ability to offer solutions to his own situations. The coacher should allot only one third of his/her time to communication while two thirds of the time are required for the active listening. (Yeung, 2000, p.22-25)

The coacher or mentor is to his customer what the teacher is to pupils or students. Regardless of the subject, the teacher must have the capacity to expose the theories pertaining to his subjectmatter. His presentation should be detailed and also differentiated, depending on the capacity of each pupil or student to understand. Thus, the entire class will understand the presented aspects. In order to emphasize the truthfulness of this theory, the teacher, through exercises, tests the exposed theory. Both the coacher and the mentor should act like a teacher for the beneficiary to reach the set objective 
Feedback is an important term from cybernetics, which means inverse reaction. Victor Sahleanuconsiders that the inverse reaction principle is important for the effective control of an action, for its correction in order to achieve the set objective. (Tran andStanciugelu, 2003, p.30)

Feedback, the central element of a coaching or mentoring process, is tightly connected to the teacher's lucidity. Without feedback, the process is irrelevant. The need for feedback is important to both the teacher and the learner. Both parties might require attitude or procedure changes. In the case of negative feedback for the coacher, he/she could be changed. Most times, it is the coacher him/herself that has to make that decision if the objective was failed and the failure attributable to him/her.

Homan and Miller add up and state that the characteristic features of a coach should be the following:

- by their nature, they are usually willing to collaborate;

- they have the capacity to see other people as competent and creative, they trust other people's ability to solve problems and make decisions;

- they share feedback in due time and require feedback for their own behaviour and impact;

- they wish what is best, not only for themselves, but for the organization and, implicitly, the team;

- they focus on the development of other people as well as on the achievement of projects and reaching of the objectives;

- When the make mistakes, they have the capacity to learn from them. (Homan and Miller, 2008, pg. 26)

Two other important features contributing to the training of an effective coacher are the capacity to establish relationships and the capacity to possess a developed intuition (Starr, 2003, p.106).

The capacity to establish relationships represents an important factor both in the private and the professional life. The establishing of sustainable professional relationships contributes to the creation of an environment that facilitates development. The coacher must have the ability to establish a relationship based on trust and reciprocity in order to both capture the attention of the trainee and to help develop the same by improving the level of trust. The efficient connection between the two participants is vital.

In the case of the coaching and mentoring relationships, one of the barriers is the poor communication between the partners. Most times, communication becomes poor further to the action of outside factors leading to the process disturbance. Such disturbing factors originate either in the personal or the professional environment. Thus, it becomes imperative that the coacher or mentor has a developed intuition in order to be able to undertake actions intended to remove the occurring barriers. Specifically, intuition is necessary in order to direct the discussion (in private) or the relationship (in general) into a comfort area so that the intended result is obtained in the end.

Ian Fleming and Allan J.D. Taylor complete the list of the qualities a coacher should possess: capacity to convince, influence and encourage others, capacity to correctly assess the baseline, current and future circumstance against the coaching process, creativity, capacity to help others and shape an idea about superior performance, capacity to believe in others and the desire to see them succeed, capacity to take the second place, the beneficiary coming first, developed sense of humour. (Fleming and Taylor, 1998, p.18-19)

In parallel, the specialty literature also points out the features that a mentor should not have. Thus, Florence Stone considers that among the features of a "bad mentor" are: dictatorial tendency - intolerant to other people's mistakes, lack of interest to the aspirations of others, critical, disloyal, distant nature, poor communication qualities, poor capacity to hold on to promises and commitments, biased viewpoints. (Stone, 2004, p.13) 


\section{Methodology}

In the paper, the Qualitative Comparative Analysis (QCA) was used as research method, which presents a high interest within the academic environment, despite having been invented over thirty years ago byCharles Rangin. (Ragin, 1987). TheQCA method comes in between the qualitative and quantitative specific methodological issues. (Dusa, 2014, p.5). As such, differences between the qualitative and quantitative analyses are eliminated .(Rihouxsi Ragin, 2009)

The fsQCA software was used to process the collected data.

\section{Findings}

Through this study, we wish to emphasize the features of coachers and mentors that influence people's desire to have a mentor or coacher. Thus, from the features listed in chapter three, we decided to include within the causes the following features of coachers and mentors: altruism, professionalism, patience, capacity to offer feedback, capacity to listen. We set out to test how these causes affect people's motivation to call for the services of a coacher or a mentor.

After the selection stage, we began the research itself. In the first stage, we established the conceptual model (Figure 1). We considered as independent variables the previously selected qualities, and dependent variable the "people's motivation to call for the services of a coacher or a mentor"

Figure no. 1. Conceptual Model

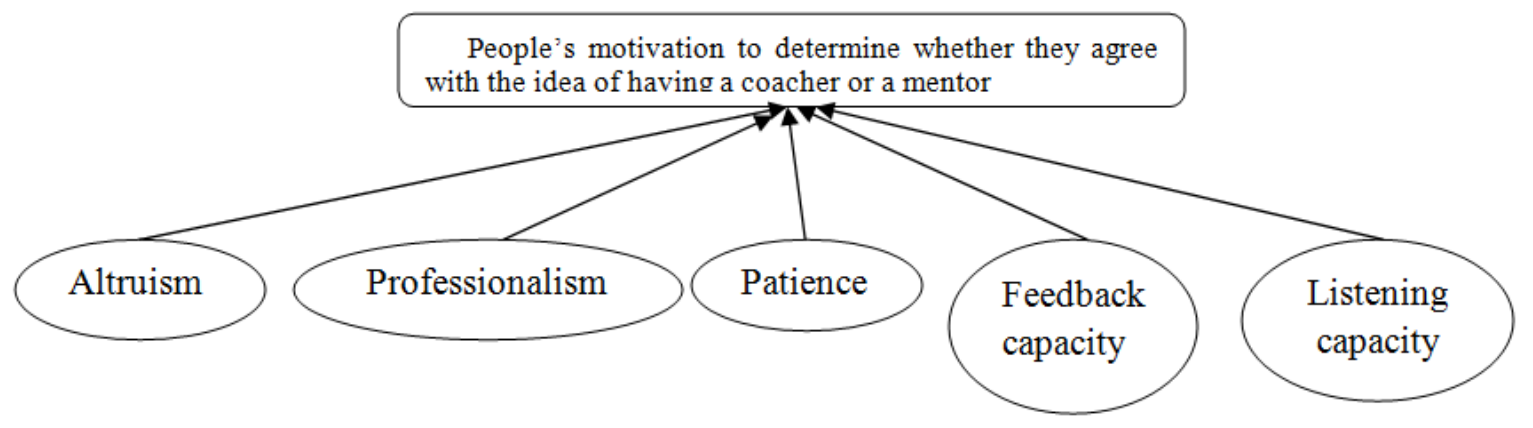

Source: Figure designed by the authors

In the next stage we collected data through a questionnaire. The sample contained twenty, higher education respondents aged between twenty-eight and thirty-two years. The assessment was made based on the Likert scale.

The results calibration process was made by correlating the Likert scale values established in the 0 to 1 fuzzy set, according to the QCA methodology, resulting into Table no. 1.

Table no. 1. Scale calibration

\begin{tabular}{|c|c|}
\hline Fuzzy set value & Likert scale correspondent \\
\hline 1 & Total agreement \\
\hline 0.75 & Agreement \\
\hline 0.5 & Neither agreement nor disagreement \\
\hline 0.25 & Disagreement \\
\hline 0 & Total disagreement \\
\hline
\end{tabular}

Source: Figure designed by the authors

Variables were later on defined: Alt for altruism, Pro for professionalism, Rab for patients, Fdb for the capacity to provide feedback, Ascf or the listening capacity and Apr for the dependant variable. Moreover, the Rez variable was defined in order to emphasize the calculated result of the causes fuzzy sets values from the conceptual model, by the relation: Rez = fuzzyand (Alt, Pro, Rab, Fdb, Asc). The "fuzzyand" function returns the minimum of the analysed variables. 
Table no. 2. Fur:y sets calibrated for the identified cases

\begin{tabular}{|c|c|c|c|c|c|c|c|}
\hline Case & Alt & Pro & Rab & Fdb & Asc & Apr & Rez \\
\hline 1 & 0.5 & 0.75 & 1 & 0.25 & 1 & 0.5 & 0.25 \\
\hline 2 & 0.5 & 0.5 & 1 & 1 & 1 & 0.5 & 0.5 \\
\hline 3 & 1 & 0.5 & 0 & 1 & 1 & 1 & 0 \\
\hline 4 & 1 & 0.75 & 0.5 & 1 & 1 & 0.75 & 0.5 \\
\hline 5 & 1 & 1 & 0.5 & 1 & 0.5 & 1 & 0.5 \\
\hline 6 & 0.75 & 0.75 & 0.75 & 1 & 0.5 & 0.75 & 0.5 \\
\hline 7 & 0.75 & 0.5 & 0 & 0.5 & 0.25 & 0.25 & 0 \\
\hline 8 & 1 & 0.75 & 0.5 & 0.25 & 0.75 & 1 & 0.25 \\
\hline 9 & 1 & 1 & 0.75 & 0.5 & 1 & 1 & 0.5 \\
\hline 10 & 1 & 1 & 0 & 0.75 & 1 & 1 & 0 \\
\hline 11 & 0.5 & 1 & 1 & 1 & 1 & 1 & 0.5 \\
\hline 12 & 0.5 & 1 & 0 & 0.25 & 1 & 0.5 & 0 \\
\hline 13 & 1 & 1 & 1 & 0.5 & 0.5 & 0.75 & 0.5 \\
\hline 14 & 1 & 1 & 0.5 & 0.5 & 0.5 & 0.75 & 0.5 \\
\hline 15 & 1 & 1 & 0.75 & 0.5 & 0.5 & 0.75 & 0.5 \\
\hline 16 & 1 & 1 & 1 & 1 & 1 & 1 & 1 \\
\hline 17 & 1 & 1 & 0 & 1 & 1 & 1 & 0 \\
\hline 18 & 1 & 1 & 0.25 & 1 & 0.5 & 1 & 0.25 \\
\hline 19 & 0.75 & 1 & 0 & 0.75 & 0.5 & 1 & 0 \\
\hline 20 & 0.5 & 0.75 & 0.25 & 0.25 & 0.75 & 0.5 & 0.25 \\
\hline
\end{tabular}

Source: Figure designed by the authors based on the data collected through the questionnaire

To start with, we decided to test the XY plane fuzzy set consistency and coverage by using the "XY plot" function. Thus, Figure no. 2 resulted, which illustrates the case distribution in the XY plane graph. It must be mentioned that the $\mathrm{X}$ axis is used in order to illustrate the Rez variable values while the $\mathrm{Y}$ axis shows the Apr variable values.

\section{Figure no.2. Case distribution in the XY plane graph}

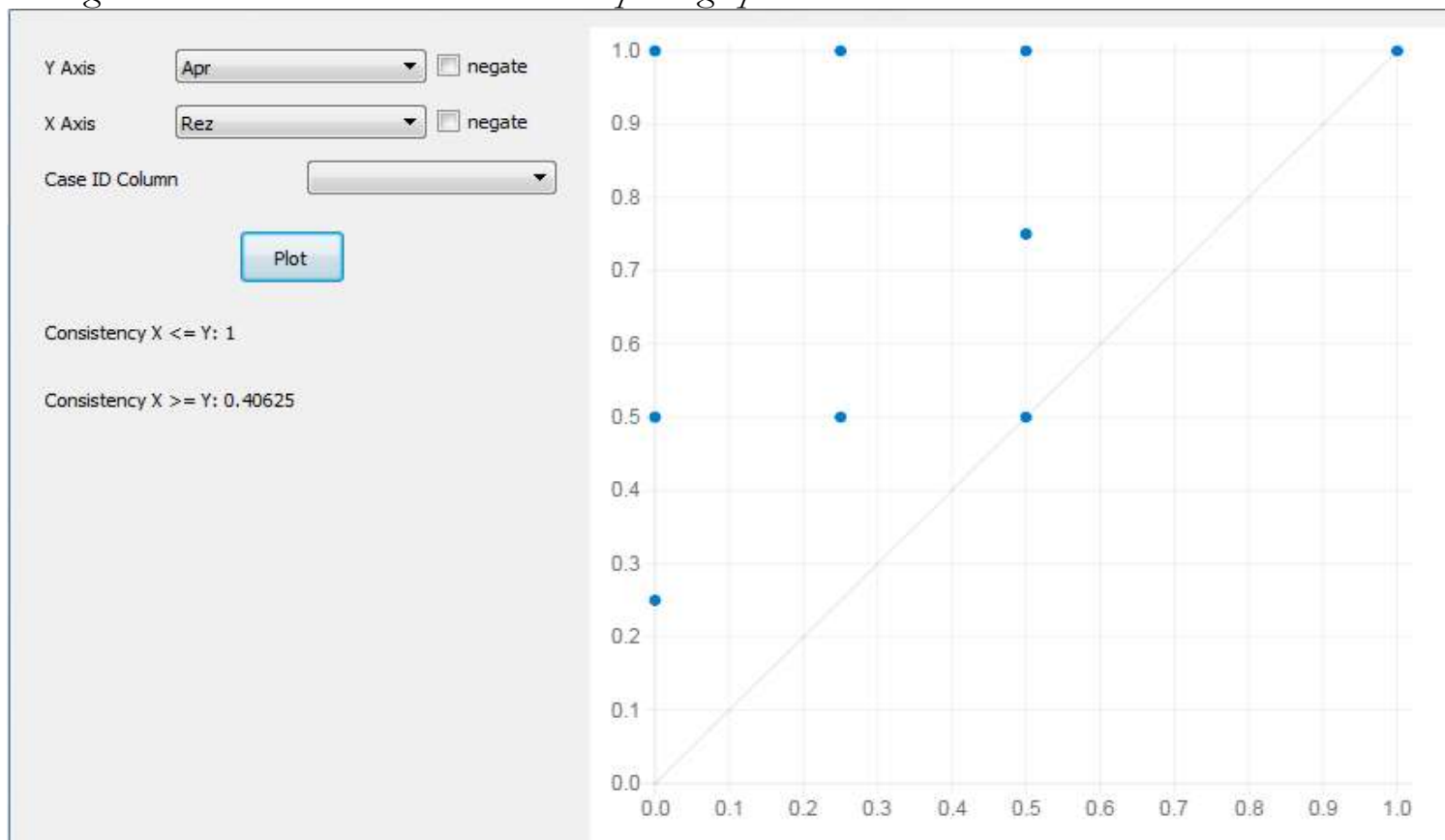

Source: Figure resulting further to the use of the XY plot function of the fsQCA software.

Analysing the result, it could be observed that in the case of $\mathrm{X}<=\mathrm{Y}$, consistency is 1 , which is 
the equivalent to the fact that the Rez variable is a subset of variable Apr. Considering that the resulting value is maximum, we could easily assert that the previous conditions are sufficient to obtain the result. The 0.40625 consistency for the $\mathrm{X}>=\mathrm{Y}$ relation means that the coverage degree is of $40.62 \%$. More specifically, the result shows that the Rez variable represents $40.62 \%$ from the sum of the Apr variable members.

The next step within the research was to emphasize the case distribution in various logical combinations of the causality conditions. (Ragin, 2017)

\section{Table no. 3. Truths table}

\begin{tabular}{|c|c|c|c|c|c|c|c|c|c|c|}
\hline Alt & Pro & Fos & Fab & Asc. & nume & & Apt & raw consit. & PRE consist. & SMM consist \\
\hline 1 & 1 & 0 & 1 & I & 2 & $(665)$ & & $t$ & 1 & 1 \\
\hline I & 1. & 1 & 1 & 1 & 1 & $(00050)$ & & $t$ & 5 & 1 \\
\hline - & 0 & 0 & a & - & 0 & 2000 & & & & \\
\hline 1 & 0 & 0 & 0 & 0 & 0 & $000 \leqslant$ & & & & \\
\hline b & 1 & 0 & a) & - & 0 & $1000 \%$ & & & & \\
\hline 1 & 1 & 0 & 0 & ? & 0 & acoss & & & & \\
\hline 0 & 0 & 1 & 0 & . & 0 & acoss & & & & \\
\hline$t$ & 0 & 1 & 0 & 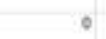 & 0 & $a 00 \%$ & & & & \\
\hline 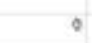 & 1 & 1 & 0 & 0 & 0 & $a 00=0$ & & & & \\
\hline 1 & 1. & 1 & 0 & 0 & 0 & $a 00 \%$ & & & & \\
\hline 0 & 0 & 0 & 1 & 。 & 0 & $000 \%$ & & & & \\
\hline 1 & 0 & 0 & 1 & $\circ$ & 0 & $000 \%$ & & & & \\
\hline$\theta$ & 1 & 0 & 1 & ? & 0 & acos & & & & \\
\hline 1 & 1 & 0 & 1 & 0 & 0 & a00\%s & & & & \\
\hline o & 0 & 1 & 1 & : & 0 & 0000 & & & & \\
\hline 1 & 0 & 1 & 1 & - & 0 & acosu. & & & & \\
\hline$\bullet$ & 1 & 1 & 1 & - & 0 & {$[000 \times)$} & & & & \\
\hline 1 & 1 & 1 & 1 & - & 0 & a00N/ & & & & \\
\hline 0 & 0 & 0 & 0 & 1 & 0 & 20000 & & & & \\
\hline 1 & 0 & 0 & 0 & 1 & 0 & $(100 \times)$ & & & & \\
\hline$\theta$ & 1 & is & 0 & 1 & 0 & $1000 \%$ & & & & \\
\hline 1 & 1 & 0 & a & 1 & 0 & $1000 \times 1$ & & & & \\
\hline 0 & 0 & 1 & 0 & 1 & 0 & 0005 & & & & \\
\hline 1 & 0 & I & 0 & 1 & 0 & a00s & & & & \\
\hline$\theta$ & 1 & 1 & 0 & 1 & 0 & acoss) & & & & \\
\hline 1 & 1 & 1 & $a$ & 1 & 0 & (1000) & & & & \\
\hline$\theta$ & 0 & 0 & 1 & 1 & 0 & $a 00 \times)$ & & & & \\
\hline 1 & 0 & 0 & 1 & 1 & 0 & acos, & & & & \\
\hline 9 & 1 & 0 & 1 & 1 & $\sigma$ & 20000 & & & & \\
\hline a & 0 & 1 & 1 & 1 & 0 & a00 $\$$ & & & & \\
\hline 1 & 0 & 1 & 1 & 1 & 0 & $a 00 \times$ & & & & \\
\hline 0 & 1 & 1 & 1 & .1 & 0 & $1000 \times)$ & & & & \\
\hline
\end{tabular}

Source: Table resulting further to the use of the True Table Algorithm function of the fsQCA software

By studying the consistency values from Table no. 3, it may be observed that only two causal combinations are valid in order to obtain the result: the one in which all independent values are possible and the one in which the Rab variable is missing. It could be seen that for the first combination one case was identified and for the second one two validated cases in the questionnaire were identified.

\section{Conclusions}

In the end, we could conclude that the performed research reached its intended purpose that of achieving an ideal portrait of a coacher or mentor and the establish the causality relation between certain features and the people's desire to have a coacher or a mentor. We believe that in order to ensure the success of the coaching process, a coacher needs not possess all the aforementioned qualities. The assertion is also strengthened by the fact that each author, from his/her perspective or due to the expertise in various fields, considers different qualities for a 
coacher to be effective. To a great extent, we consider we have managed to sketch the general ideal portrait of a coacher. Therewith, we think that this portrait requires modifications depending on the coacher's or mentor's field of activity. The outside environment in which the beneficiary organizations perform their activity should also be brought into the discussion. That is why we consider that this portrait requires modifications depending on the macroeconomic conditions of each country. Thus, we could emphasize that a coacher should have increased adaptability considering that there are even organizational culture differences amongst the entities from different regions of the same country or even amongst the various branches in the same country. We consider we took the first step within a study intended to be wider - that of defining the optimum coacher's portrait in Romania, a step that will be developed in a further paper by including among the causes all the identified features and the size of the questionnaire respondents' sample.

Questions might arise, which refer to the need of such study. The starting basis was that of costs and performance. We consider that a generally valid relationship can be achieved between the two variables, the organizations' outside environment being the defining element causing the oscillation of the two variables. If costs are not considered, we could easily say that any organization should contract the services of an as developed as possible coacher, whose portrait comprises as many as possible of the features we identified. If budget restriction is considered, then the number of possible variants is reduced. That is why an ideal portrait to the local market that has maximum effects with minimum costs should be identified.

\section{References}

1. Amin, Z., A., 2017., Learnin Process- Theories, Principles and Characteristics, [online] Available at: https:/ / mwn.slideshare.net/ zulfiquer732/ learning-process-theories-principles-and-characteristics-lecture11 [Accessed on 4 May 2019]

2. Dusa, A., 2014., Elements of comparative analysis, Bucharest: Tritonic.

3. Fleming, I., Taylor, A.J.D., 1998., The coaching pocketbook., Unitek Kingdom: Management Pocketbooks Ltd.

4. Hernez-Broome, G., Boyce, L.A., 2011, Advancing Executive Coaching. Setting the Course for Successful Leadership Coaching., San Francisco: Jossey-Bass A Wiley Imprint

5. Homan, M. and Miller, L. J., 2008., Coaching in organizations. Best coaching practices from the Ken Blanchard Companies, New Jersey: John Wiley \& Sons Inc

6. Ragin, C., 1987., The comparative method. Moving beyond qualitative and quantitative strategies., Berkeley, Los Angeles \& London: University of California Press

7. Ragin, C., 2017., User's guide to Fuzry-Set Qualitative Comparative Analysis 3.0., Irvine, California: Department of Sociology, University of California

8. Reeves, D.B., Allison, E., 2010., Renewal Coaching Workbook, San Francisco: Jossey-Bass

9. Rihoux, B., Ragin, C., 2009., Configurational comparative methods: Qualitative Comparative Analysis (QCA) and related techniques., Thousand Oaks, California: Sage.

10. Schein, E. H., 2009., Helping: How to offer, give, and receive help., San Francisco: Berrett - Koebler

11. Starr, J., 2003., The Coaching Manual. The definitive guide to the process, principles and skill of personal coaching., Great Britain: Pearson Education Limited

12. Stone, F., 2004., The mentoring advantage. Creating the next generation of leaders., United States of America: Dearborn Trade Publishing

13. Tran, V., Stanciugelu, I., 2003., Theory of communication, Bucharest: Comunicare.ro

14. Yeung, R., 2000., The things that really matter about Coaching People., Oxford: HowTo Books Ltd. 